\title{
KHẢO SÁT TIẾN TRIỂN CỦA ĐÁI THÁO ĐƯờNG THAI KỲ SAU SINH
}

\author{
Phan Thị Tố Nhur', Hoàng Trung Vinh ${ }^{2}$ \\ 1. Đại học Dược Hà Nội \\ 2. Học viện Quân y
}

DOI: $10.47122 / v j d e .2020 .41 .11$

\section{ABSTRACT \\ Investigation of the progress in the women with gestational diabetes mellitus postpartum}

Objective: Our aim was to evaluate the uptake of postpartum screening, the prevalence and the risk factors for glucose intolerance in women with a recent history of gestational diabetes mellitus (GDM). Methods: All women with a history of GDM are advised to undergo a $75 \mathrm{~g}$ oral glucose tolerance test (OGTT) around 6 - 12 weeks postpartum. Indices of insulin sensitivity (the Matsuda index and the reciprocal of the homeostasis model assessment of insulin resistance, HOMA-IR) and an index of betacell function, the Insulin Secretion-Sensitivity Index-2 (ISSI-2) were calculated based on the OGTT postpartum. Multivariable logistic regression was used to some factors. Results: Of all women (135) who received an OGTT postpartum, $42.2 \%$ (57) had prediabetes (11.8\% impaired fasting glucose, $24.4 \%$ impaired glucose tolerance and $6.0 \%$ both impaired fasting and impaired glucose tolerance) and $1.5 \%$ (2) had overt diabetes. Compared to women with a normal OGTT postpartum, women with glucose intolerance and diabetes were older $(32.5 \pm 4.3$ vs. $30.8 \pm$ 4.8 years, $\mathrm{p}=0.049$ ), were more often obese $(34.5 \%$ vs. $17.3 \%, p=0.023)$. In the multivariable logistic regression, an EM background $[\mathrm{OR}=2.76(1.15-6.62), \mathrm{p}=$ 0.023] and the HbA1c level at the time of the OGTT in pregnancy [OR $=4.78(1.19$ 19.20), $\mathrm{p}=0.028$ ] remained significant predictors for glucose intolerance postpartum. Women with glucose intolerance and diabetes postpartum had a similar insulin sensitivity [Matsuda index $0.656(0.386$ - 1.224) vs. 0.778 (0.532 - 1.067), $\mathrm{p}=0.709$; HOMA-IR $0.004(0.002-0.009)$ vs. $0.064(0.003-$
0.007), $\mathrm{p}=0.384$ ] but a lower beta-cell function compared to women with a normal OGTT postpartum, remaining significant after adjustment for confounders [ISSI-2 1.6 (1.2 $2.1)$ vs. $1.9(1.7-2.4), \mathrm{p}=0.002]$. Conclusions: Glucose intolerance is very frequent in early postpartum in women with GDM these women have an impaired betacell function. Nearly one third of women did not attend the scheduled OGTT postpartum and these women have an adverse risk profile. More efforts are needed to engage and stimulate women with GDM to attend the postpartum OGTT.

Keywords: Gestational Diabetes, Prediabetes, Oral glucose tolerance test, Impaired fasting glucose, Impaired glucose tolerance, Diabetes, Insulin resistance.

\section{TÓM TẮT}

Muc tiêu: Đánh giá dung nạp glucose sau sinh 6 - 12 tuần và mối liên quan với một số yếu tố ở phụ nữ có tiền sử đái tháo đường thai kỳ (ĐТÐТК). Đối tượng và phương pháp nghiên cúv: 135 phụ nữ có tiền sử ĐТĐТК được thực hiện nghiệm pháp dung nạp glucose đường uống (NPDNG) sau $6-12$ tuần kể từ khi sinh. Các chỉ số đánh giá nhạy cảm insulin bao gồm chỉ số Matsuda, HOMAIR và chức năng tế bào $\beta$ (ISS1-2) dựa vào dung nạp glucose. Xác định tương quan hồi quy đa biến với một số yếu tố. Kết quả: 47/135 (42,2\%) biểu hiện rối loạn dung nạp glucose (tiền ĐTĐ) trong đó 11,8\% tăng glucose lúc đói (IFG - Impaired Fasting Glucose); 24,4\% giảm dung nạp glucose (IGT - Impaired Glucose Tolerance); 6\% phối hợp cả hai biểu hiện trên và $1,5 \%(2 / 135)$ đái tháo đường (ĐTĐ). So sánh với nhóm có dung nạp glucose bình thường nhận thấy: nhóm có rối loạn dung nạp glucose và ĐTĐ có tuổi cao hơn $(32,5 \pm 4,35$ so với $30,8 \pm 4,8, \mathrm{p}=$ 
0,049); tỷ lệ thừa cân, béo phì cao hơn $(34,5 \%$ so với $17,3 \%, p=0,023)$; thời gian tồn tại glucose máu lúc đói bất thường dài hơn $(55,6 \%$ so với $37,3 \%, p=0,04)$. Phân tích hồi quy đa biến nhận thấy: giảm cân nặng sau sinh [OR = 2,76 $(1,15-6,62), p=0,023$ ] và chỉ số $\mathrm{HbAlc}$ tại thời điểm thực hiện NPDNG khi mang thai [OR $=4,78(1,19-$ $19,20), p=0,028$ ] là yếu tố tiên lượng độc lập gây rối loạn dung nạp glucose sau sinh. Phụ nữ rối loạn dung nạp glucose và ĐTĐ sau sinh có độ nhạy insulin tương đương, biểu hiện bởi chỉ số Matsuda: 0,656 (0,386 $1,224)$ so với $0,778(0,532-1,067), \mathrm{p}=$ 0,709; HOMA-IR là $0,004(0,002-0,009)$ so với $0,064(0,03-0,07), p=0,0384$ nhưng chức năng tế bào $\beta$ thâp hơn, ISSI- $2=1,6$ $(1,2-2,1)$ so với $1,9(1,7-2,4) \mathrm{p}=0,002$ so với đối tượng có dung nạp glucose máu bình thường. Kết luận: Rối loạn dung nạp glucose hay gặp ở giai đoạn sớm sau đẻ trong số phụ nữ có ĐTĐTK với biểu hiện giảm chức năng tiết insulin của tế bào $\beta$. Cần nỗ lực hơn để những phụ nữ ĐTĐTK thực hiện NPDNG sau sinh.

Tù khóa: Đái tháo đường thai kỳ, rối loạn glucose lúc đói, tiền đái tháo đường, nghiệm pháp dung nap glucose, giảm dung nap glucose, đái tháo đuoòng, kháng insulin.

Chịu trách nhiệm chính: Phan Thị Tố Như

Ngày nhận bài: 12/8/2020

Ngày phản biện khoa học: 12/9/2020

Ngày duyệt bài: 15/10/2020

Email: hieunhu_1983@yahoo.com

Điện thoại: 0982150802

\section{1. ĐẶT VẤN ĐỀ}

Những biến đổi ở phụ nữ mang thai liên quan đến chuyển hóa carbohydrat thông qua biến đổi các hormon đặc biệt thời kỳ mang thai gây biến đổi nồng độ và biểu hiện kháng insulin ở ngoại vi dẫn đến tăng glucose. Tất cả những biến đổi nêu trên xuất hiện nhằm duy trì glucose máu bình thường trong quá trình mang thai [1].

ĐTĐTK là một trong bệnh chuyển hóa rất hay gặp ở phụ nữ mang thai [2]. Nếu theo dõi lâu dài sau đẻ những phụ nữ này có nguy cơ gia tăng bệnh ĐTĐ type 2 và biến chứng tim mạch ở những giai đoạn sau đó [3]. Tồn tại một số yếu tố nguy cơ làm gia tăng tiến triển ĐTĐTK thành ĐTĐ type 2 bao gồm dư cân, béo phì, tiền sử gia đình có ĐTĐ, tiền sử tăng huyết áp, tiền ĐTĐ, tuổi cao, số lần sinh đẻ.

Những phụ nữ có rối loạn dung nạp glucose hoặc ĐTĐTK cần được theo dõi và có biện pháp can thiệp thích hợp để đảo ngược hoặc làm chậm tiến triển những rối loạn đã có trước đó. Trong thời gian 3 tháng sau đẻ ở những đối tượng có rối loạn dung nạp glucose máu khi mang thai cần được thực hiện các test chẩn đoán dựa vào khuyến cáo của ADA.

Đề tài nghiên cứu nhằm mục tiêu đánh giá dung nạp glucose 6-12 tuần sau sinh và mối liên quan với một số yếu tố ở phụ nữ có tiền sử đái tháo đường thai kỳ.

\section{2. ĐỐI TƯợNG VÀ PHƯƠNG PHÁP NGHIÊN CÚU}

2.1. Đối tượng

135 phụ nữ tuổi từ 19 - 39, có tiền sử ĐTĐTK thuộc đối tượng nghiên cứu thu thập tại Bệnh viện Phụ sản Hà Nội theo mẫu thuận tiện.

\subsubsection{Tiêu chuẩn lụa chọn}

+ Phụ nữ có tiền sử ĐTĐTK phát hiện ở tuần 24-28 của thời kỳ mang thai.

+ Thời gian quan sát sau đẻ 6-12 tuần.

+ Có hay không có điều trị ĐTĐTK bằng tiết chế ăn uống hoặc dùng insulin khi mang thai.

+ Không dùng insulin trong 12 tuần sau đẻ.

+ Đồng ý tham gia nghiên cứu.

\subsubsection{Tiêu chuẩn loại trù̀}

+ Mắc ĐTĐ trước khi mang thai

+ Đang mắc các bệnh nhiễm trùng cấp tính

+ Mắc một số bệnh mạn tính như suy gan, suy thận, suy tim.

+ Mắc một số bệnh nội tiết khác kết hợp như Basedow, cường hoặc suy chức năng tuyến giáp, hội chứng Cushing.

+ Đang dùng corticoid hoặc các thuốc ảnh hưởng lên glucose. 
+ Không đồng ý tham gia nghiên cứu.

\subsection{Phương pháp}

- Thiết kế nghiên cứu: Tiến cứu kết hợp hồi cứu, quan sát, mô tả không đối chứng.

- Nội dung quan sát, xét nghiệm:

+ Khai thác tiền sử sức khỏe, thai sản, tiền sử gia đình mắc ĐTĐ.

+ Thu thập các thông tin, xét nghiệm liên quan đến ĐTĐTK đã được chẩn đoán khi mang thai.

+ Các biện pháp đã điều trị ĐTĐTK trong quá trình mang thai.

+ Khám lâm sàng các cơ quan tại thời điểm nghiên cứu.

+ Xác định chỉ số khối cơ thể (BMI).

+ Xét nghiệm đồng thời glucose, insulin và $\mathrm{HbA1c}$ lúc đói.

+ Làm nghiệm pháp dung nạp glucose đường uống tại thời điểm sau sinh 6-12 tuần với 75 gram glucose khan pha với $200 \mathrm{ml}$, uống trong 5 phút. Xét nghiệm glucose máu sau 1 giờ, 2 giờ.

+ Xác định các chỉ số kháng insulin và chức năng tế bào $\beta$ dựa vào glucose và insulin đồng thời lúc đói bao gồm ISSI-2, chỉ số Matsuda, HOMA-IR.

\subsection{Tiêu chuẩn chẩn đoán, phân loại sử dụng trong nghiên cứu \\ - Chẩn đoán ĐTĐTK theo khuyến cáo của} ADA (2011) và WHO (2013):

+ Glucose máu lúc đói từ 5,1 - 6,9 mmol/l hoặc:

+ Glucose máu sau $1 \mathrm{~h}$ làm NPDNG $\geq 10,0$ mmol/1 hoặc:

+ Glucose máu sau $2 \mathrm{~h}$ làm NPDNG từ 8,5 - 11,0 mmol/l.

- Chẩn đoán tiền ĐTĐ theo khuyến cáo của ADA (2019):

+ IFG: 5,6 - 6,9 mmol/1 hoặc:

+ IGT: 7,8 - 11,0 mmol/1 hoặc:

+ HbA1c: 5,7 - 6,4\%.

- Chẩn đoán ĐTĐ theo khuyến cáo của $\operatorname{ADA}(2019)$ :

+ Glucose máu lúc đói $\geq 7$ mmol/1 hoặc:

+ Glucose máu sau 2h làm NPDNG $\geq 11,1$ mmol/1 hoặc:

+ HbA1c $\geq 6,5 \%$ hoặc:

+ Glucose máu bất kỳ $\geq 11,1 \mathrm{mmol} / 1$ và kèm theo triệu chứng cổ điển của ĐTĐ.

- Phân loại BMI theo tiêu chuẩn của WHO (2000) cho người Châu Á - Thái Bình Dương:

\begin{tabular}{|l|c|}
\hline \multicolumn{1}{|c|}{ Phân loại } & BMI $\mathbf{( k g / \mathbf { m } ^ { 2 } )}$ \\
\hline Thiếu cân & $<18,5$ \\
\hline Bình thường & $18,5-22,9$ \\
\hline Thừa cân & $\geq 23$ \\
\hline Béo phì độ I & $25-29,9$ \\
\hline Béo phì độ II & $\geq 30,0$ \\
\hline
\end{tabular}

2.4. Xử lý số liệu

+ Sử dụng phần mềm xử lý thống kê SPSS 22.0.

+ Xác định, so sánh giá trị trung bình, tỷ lệ \% nếu số liệu phân bố liên tục theo luật chuẩn hoặc trung vị khi phân bố không theo luật chuẩn.

+ So sánh bằng các thuật toán: T-test, Mann-Whitney’s, U test hoặc chi - Squared.

\section{5. Đạo đức y học trong nghiên cứu}

+ Nghiên cứu không vi phạm đạo đức y học.

+ Đề cương nghiên cứu được thông qua Hội đồng Khoa học của Bệnh viện Phụ sản Hà Nội.

+ Đối tượng nghiên cứu không phải chi trả bất kỳ khoản nào.

\section{KẾT QUẢ NGHIÊN CÚU}

Bảng 3.1. Phân bố $B N$ theo tình trạng dung nạp glucose $(n=135)$

\begin{tabular}{|c|c|c|c|}
\hline \multicolumn{2}{|c|}{ Chỉ số } & Số BN (n) & Tỷ lệ (\%) \\
\hline \multicolumn{2}{|c|}{ Dung nạp bình thường } & 76 & 56,3 \\
\hline Rối loạn dung nạp & IFG & 16 & 11,8 \\
\hline
\end{tabular}




\begin{tabular}{|l|l|c|c|}
\hline glucose và ĐTĐ & IGT & 33 & 24,4 \\
\cline { 2 - 4 } & IFG + IGT & 8 & 6 \\
\cline { 2 - 4 } & ĐTĐ & 2 & 1,5 \\
\hline
\end{tabular}

\begin{tabular}{|l|c|c|}
\hline \multicolumn{1}{|c|}{ Chỉ số } & Số BN (n= 135) & Tỷ lệ (\%) \\
\hline Dung nạp bình thường & 76 & 56,3 \\
\hline Rối loạn dung nạp & 57 & 42,2 \\
\hline ĐTÐ & 2 & 1,5 \\
\hline
\end{tabular}

\begin{tabular}{|l|c|c|}
\hline \multicolumn{1}{|c|}{ RLDNG } & Số BN (n= 57) & Tỷ lệ (\%) \\
\hline IFG & 16 & 28,1 \\
\hline IGT & 33 & 57,9 \\
\hline IFG + IGT & 8 & 14,0 \\
\hline
\end{tabular}

Chú thích: thời gian trung bình thực hiện NPDNG: 10 (6-12) tuần.

Nhận xét:

+ Rối loạn dung nạp glucose gặp với tỷ lệ thấp hơn so với dung nạp bình thường $(42,2 \%$ so với $56,3 \%)$.

+ Trong số rối loạn dung nạp glucose thì IGT chiếm tỷ lệ cao nhất $(24,4 \%)$.

+ 3 tháng sau đẻ có 2 đối tượng chuyển ĐTĐ type $2(1,5 \%)$.

Bảng 3.2. So sánh một số đặc điểm giữa nhóm có dung nạp glucose bình thường và nhóm có rối loạn dung nạp glucose/ ĐTĐ sau sinh

\begin{tabular}{|l|c|c|c|}
\hline \multicolumn{1}{|c|}{ Chỉ số } & $\begin{array}{c}\text { Dung nạp bình } \\
\text { thường } \\
(\mathbf{n = 7 6 )}\end{array}$ & $\begin{array}{c}\text { RL dung nạp/ } \\
\text { ĐTĐ (n= 59) }\end{array}$ & $\mathbf{p}$ \\
\hline Tuối trung bình (năm) & $30,8 \pm 4,8$ & $32,5 \pm 4,3$ & $\mathbf{0 , 0 4 9}$ \\
\hline BMI TB lần đầu trước sinh & $25,4 \pm 5,5$ & $27,2 \pm 5,6$ & $\mathbf{0 , 0 3 5}$ \\
\hline Tăng cân nặng trung bình & $15,0 \pm 1,7$ & $15,4 \pm 2,0$ & 0,658 \\
\hline Tiền sử gia đình ĐTĐ & $11,8 \%$ & $11,9 \%$ & 0,084 \\
\hline Tiền sử THA & $6,6 \%$ & $15,3 \%$ & 0,101 \\
\hline Sinh đẻ nhiều lần & $60,5 \%$ & $59,3 \%$ & 0,887 \\
\hline $\begin{array}{l}\text { Thời gian TB làm NPDN trước mang } \\
\text { thai (tuần) }\end{array}$ & $22,5(24,2-26,2)$ & $25,0(24,0-26,7)$ & 0,671 \\
\hline GTTB glucose của NPDN (mmol/1) & $8,5(8,02-9,7)$ & $9,4(8,55-10,44)$ & 0,059 \\
\hline $\begin{array}{l}\text { Bất thường glucose khi làm NP lúc } \\
\text { mang thai }\end{array}$ & $37,3 \%$ & $55,6 \%$ & $\mathbf{0 , 0 4}$ \\
\hline $\begin{array}{l}\text { Bất thường glucose sau 1h làm NP } \\
\text { lúc mang thai }\end{array}$ & $48,0 \%$ & $40,7 \%$ & 0,414 \\
\hline $\begin{array}{l}\text { Bất thường glucose sau 2h làm NP } \\
\text { lúc mang thai }\end{array}$ & $62,7 \%$ & $53,7 \%$ & 0,307 \\
\hline $\begin{array}{l}\text { Glucose } \geq 2 \text { giá trị bt khi làm NP lúc } \\
\text { mang thai }\end{array}$ & $40,0 \%$ & $40,7 \%$ & 0,933 \\
\hline $\begin{array}{l}\text { Glucose } \geq 3 \text { giá trị bt khi làm NP lúc } \\
\text { mang thai }\end{array}$ & $9,3 \%$ & $9,3 \%$ & 0,989 \\
\hline
\end{tabular}




\begin{tabular}{|l|c|c|c|}
\hline $\begin{array}{l}\text { GTTB } \mathrm{HbA}_{1} \mathrm{c} \text { khi làm NP lúc mang } \\
\text { thai }\end{array}$ & $5,0 \%(4,8-5,2)$ & $5,1 \%(5,0-5,4)$ & $\mathbf{0 , 0 0 1}$ \\
\hline Tỷ lệ tăng insulin & $18,7 \%$ & $28,8 \%$ & 0,164 \\
\hline $\begin{array}{l}\text { TGTB bắt đầu dùng insulin khi mang } \\
\text { thai (tuần) }\end{array}$ & $29,2(27,7-31,0)$ & $28,0(50,0-30,2)$ & 0,316 \\
\hline
\end{tabular}

Nhận xét:

+ Đối tượng rối loạn dung nạp glucose/ ĐTĐ có tuổi, tỷ lệ béo trước sinh, tỷ lệ rối loạn dung nạp glucose khi mang thai và $\mathrm{HbA1c}$ tại thời điểm thực hiện nghiệm pháp dung nạp đều cao hơn so với nhóm có dung nạp glucose bình thường.

+ Các chỉ số khác tương đương nhau giữa hai nhóm.

Bảng 3.3. Giá trị tiên lượng độc lập rối loạn glucose sau sinh

\begin{tabular}{|l|c|c|c|c|}
\hline \multicolumn{1}{|c|}{ Chỉ số } & Độ tự do & Sai số chuẩn & OR (95\% CI) & p \\
\hline Tuối & 1 & 0,43 & $1,07(0,98-1,16)$ & 0,123 \\
\hline BMI trước mang thai & 1 & 0,036 & $1,04(0,97-1,12)$ & 0,218 \\
\hline Tiền sử gia đình ĐTĐ & 1 & 0,61 & $0,91(0,28-2,99)$ & 0,877 \\
\hline Tiền sử THA & 1 & 0,65 & $2,35(0,66-8,42)$ & 0,188 \\
\hline Sinh đẻ nhiều lần & 1 & 0,44 & $0,53(0,22-1,25)$ & 0,149 \\
\hline Giảm cân nặng sau sinh & 1 & 0,21 & $2,76(1,15-6,62)$ & $\mathbf{0 , 0 2 3}$ \\
\hline Tuần làm NPDN & 1 & 0,20 & $0,85(0,57-1,27)$ & 0,426 \\
\hline Kết quả NPDN & 1 & 0,02 & $1,01(0,98-1,03)$ & 0,525 \\
\hline IFG của NPDN khi mang thai & 1 & 0,01 & $1,00(0,99-1,01)$ & 0,559 \\
\hline $\begin{array}{l}\text { Glucose sau 1h làm NPDN khi } \\
\text { mang thai }\end{array}$ & 1 & 0,01 & $0,99(0,98-1,00)$ & 0,125 \\
\hline $\begin{array}{l}\text { Glucose sau 2h làm NPDN khi } \\
\text { mang thai }\end{array}$ & 1 & 0,40 & $0,71(0,32-1,57)$ & 0,397 \\
\hline $\begin{array}{l}\text { Glucose của NP khi mang thai } \geq \\
\text { 2 giá trị bt }\end{array}$ & 1 & 0,68 & $0,64(0,17-2,44)$ & 0,518 \\
\hline $\begin{array}{l}\text { Glucose của NP khi mang thai } \geq \\
\text { 3 giá trị bt }\end{array}$ & 1 & 0,71 & $4,78(1,19-19,2)$ & $\mathbf{0 , 0 2 8}$ \\
\hline $\begin{array}{l}\text { HbAlc tại thời điểm làm NP khi } \\
\text { mang thai }\end{array}$ & 1 & 0,47 & $1,16(0,46-2,93)$ & 0,753 \\
\hline Insulin & 1 & 0,11 & $0,97(0,78-1,21)$ & 0,801 \\
\hline $\begin{array}{l}\text { Tuần bắt đầu dùng insulin khi } \\
\text { mang thai }\end{array}$ & 1 & 1 & 0,240 \\
\hline
\end{tabular}

Nhận xét: Giảm cân nặng sau sinh và chỉ số HbA1c tại thời điểm thực hiện nghiệm pháp dung nạp khi mang thai là yếu tố tiên lượng độc lập của rối loạn dung nạp glucose.

Bảng 3.4. So sánh chỉ số chức năng tế bào $\beta$ và độ nhạy insulin giữa nhóm có dung nạp glucose bình thường và nhóm có rối loạn dung nạp glucose/ ĐTĐ sau sinh

\begin{tabular}{|c|c|c|c|c|}
\hline Chỉ số & $\begin{array}{c}\text { Dung nạp bình thường } \\
(\mathbf{n}=\mathbf{7 6})\end{array}$ & $\begin{array}{c}\text { Rối loạn dung nạp/ } \\
\text { ĐTÐ (n= 59) }\end{array}$ & $\mathbf{p}$ & $\begin{array}{c}\mathbf{p} \\
\text { hiệu } \\
\mathbf{c h i ̉ n h}\end{array}$ \\
\hline ISSI-2 & $1,9(1,7-2,4)$ & $1,6(1,2-2,1)$ & $<\mathbf{0 , 0 0 0 1}$ & 0,002 \\
\hline $\begin{array}{c}\text { Chỉ số } \\
\text { Matsuda }\end{array}$ & $0,778(0,532-1,067)$ & $0,656(0,386-1,224)$ & 0,279 & 0,709 \\
\hline HOMA-IR & $0,004(0,003-0,007)$ & $0,004(0,002-0,009)$ & 0,699 & 0,384 \\
\hline
\end{tabular}


Nhận xét: Chỉ số tiết insulin ở phụ nữ sau sinh rối loạn dung nạp glucose giảm có ý nghĩa so với nhóm không có rối loạn $(\mathrm{p}<0,0001)$.

Bảng 3.5. So sánh một số đặc điểm giữa 2 phân nhóm IFG và IGT sau sinh

\begin{tabular}{|l|c|c|c|}
\hline \multicolumn{1}{|c|}{ Chỉ số } & IFG $(\mathbf{n = 1 6 )}$ & IGT (n= 33) & p \\
\hline Tuổi trung bình & $32,0 \pm 5,3$ & $33,5 \pm 3,6$ & 0,255 \\
\hline BMI trước sinh & $31,3 \pm 4,4$ & $25,2 \pm 4,8$ & $<\mathbf{0 , 0 0 0 1}$ \\
\hline Tiền sử gia đình ĐTĐ & $18,8 \%$ & $12,1 \%$ & 0,659 \\
\hline THA trước mang thai & $12,5 \%$ & $9,1 \%$ & 0,712 \\
\hline Sinh đẻ nhiều lần & $50,0 \%$ & $60,6 \%$ & 0,482 \\
\hline Tuần làm NPDNG & $25,5(24,6-27,1)$ & $25,0(24,0-27,5)$ & 0,667 \\
\hline Glucose TB của NPDN & $8,2(6,7-9,1)$ & $9,5(8,7-10,7)$ & $\mathbf{0 , 0 1 6}$ \\
\hline $\begin{array}{l}\text { Bất thường glucose khi làm NP lúc mang } \\
\text { thai }\end{array}$ & $80,0 \%$ & $43,3 \%$ & $\mathbf{0 , 0 2}$ \\
\hline $\begin{array}{l}\text { Bất thường glucose sau 1h làm NP lúc } \\
\text { mang thai }\end{array}$ & $40,0 \%$ & $40,0 \%$ & 1,00 \\
\hline $\begin{array}{l}\text { Bất thường glucose sau 2h làm NP lúc } \\
\text { mang thai }\end{array}$ & $33,3 \%$ & $66,7 \%$ & $\mathbf{0 , 0 3 4}$ \\
\hline $\begin{array}{l}\text { Glucose của NP khi mang thai } \geq 2 \text { giá trị } \\
\text { bt }\end{array}$ & $40,0 \%$ & $46,7 \%$ & 0,671 \\
\hline $\begin{array}{l}\text { Glucose của NP khi mang thai } \geq 3 \text { giá trị } \\
\text { bt }\end{array}$ & $13,3 \%$ & $3,3 \%$ & 0,205 \\
\hline Glucose TB của NPDN khi mang thai & $5,3(5,2-5,6)$ & $5,04(4,5-5,1)$ & $\mathbf{0 , 0 1 2}$ \\
\hline Glucose sau 1h làm NPDN khi mang thai & $8,4(7,7-11,4)$ & $9,6(9,2-10,9)$ & 0,306 \\
\hline Glucose sau 2h làm NPDN khi mang thai & $6,4(6,1-8,8)$ & $8,8(8,0-9,3)$ & $\mathbf{0 , 0 0 6}$ \\
\hline Tăng insulin & $31,3 \%$ & $21,2 \%$ & 0,444 \\
\hline Tuần bắt đầu dùng insulin khi mang thai & $28,0(20,5-32,5)$ & $29,0(27,0-31,0)$ & 0,530 \\
\hline
\end{tabular}

Nhận xét:

+ Đối tượng giảm dung nạp glucose (IGT) có BMI trước sinh, tỷ lệ béo phì trước sinh, tỷ lệ dung nạp bất thường khi mang thai, giá trị trung bình glucose máu lúc đói đều thấp hơn có ý nghĩa so với đối tượng có tăng glucose máu lúc đói (IFG).

+ Ngược lại đối tượng IGT có tỷ lệ dung nạp bất thường giờ thứ 2 cũng như nồng độ glucose giờ thứ 2 của nghiệm pháp dung nạp khi mang thai cao hơn có ý nghĩa so với phân nhóm IFG.

Bảng 3.6. So sánh chỉ số chức năng tế bào $\beta$ và kháng insulin giữa 2 phân nhóm IFG và IGT sau sinh

\begin{tabular}{|l|c|c|c|c|}
\hline \multicolumn{1}{|c|}{ Chỉ số } & IFG (n= 16) & IGT $(\mathbf{n}=\mathbf{3 3})$ & $\mathbf{p}$ & $\begin{array}{c}\text { P sau } \\
\text { hiệu chỉnh }\end{array}$ \\
\hline ISSI-2 & $1,7(1,1-2,2)$ & $1,6(1,3-2,1)$ & 0,890 & 0,610 \\
\hline $\begin{array}{l}\text { Chỉ số } \\
\text { Matsuda }\end{array}$ & $0,441(0,365-1,527)$ & $0,696(0,414-1,160)$ & 0,396 & 0,977 \\
\hline HOMA-IR & $0,003(0,002-0,007)$ & $0,005(0,002-0,009)$ & 0,209 & 0,737 \\
\hline
\end{tabular}


Nhận xét: Giá trị các chỉ số ISSI-2, Matsuda, HOMA-IR giữa hai phân nhóm khác biệt không có ý nghĩa thống kê.

\section{BÀN LUẬN}

Đái tháo đường thai kỳ (ĐTĐТK) sau sinh diễn biến theo nhiều chiều hướng khác nhau, có thể thay đổi tình trạng hoặc hoán vị cho nhau. Đa số trường hợp có thể trở về bình thường do các rối loạn hormon - nội tiết liên quan được phục hồi, cơ thể tự điều chỉnh song cũng có không ít trường hợp vẫn tồn tại biểu hiện rối loạn dung nạp dưới dạng IFG và/ hoặc IGT. Một số ít trường hợp chuyển sang ĐTĐ thực thể [5]. Trong số đối tượng ĐTĐTK được khảo sát tại thời điểm 6 - 12 tuần sau sinh nhận thấy 42,2\% (57/135) biểu hiện rối loạn dung nạp glucose dạng đơn độc hoặc phối hợp, chỉ có $1,5 \%$ trường hợp ĐTĐ. Nếu tính riêng tỷ lệ trong nhóm rối loạn dung nạp glucose thì $57,9 \%$ có IGT; $28,1 \%$ có IFG và $14,0 \%$ phối hợp cả hai. Trong số đối tượng nghiên cứu có $23,2 \%$ phụ nữ đã phải sử dụng insulin để điều trị ĐTĐTK. Tỷ lệ trên cũng tương đương so với nghiên cứu thuần tập của Duran A và cs [6].

Nếu đánh giá dựa vào $\mathrm{HbA} 1 \mathrm{c}$ đơn thuần hoặc phối hợp với dung nạp glucose ở phụ nữ mắc ĐTĐTK sẽ cho kết quả trái ngược với tỷ lệ độ nhạy của $\mathrm{HbAlc}$ và glucose khi thực hiện nghiệm pháp phối hợp với nhau dao động từ $83 \%$ đến $90 \%$ [7].

Trong các yếu tố nguy cơ gây rối loạn dung nạp glucose sau sinh nhận thấy thừa cân, béo phì liên quan có ý nghĩa. Theo đó, đối tượng IFG có biểu hiện béo phì cao hơn so với IGT tại thời điểm thực hiện NPDNG khi mang thai. Một số tác giả cho rằng đối tượng IFG thời gian đầu sau sinh có độ nhạy insulin thấp hơn so với IGT. Tuy vậy kết quả khảo sát của đề tài không nhận thấy sự khác biệt của các chỉ số chức năng tế bào $\beta$ và độ nhạy insulin giữa hai phân nhóm trên. Cũng có thể do số lượng đối tượng còn ít và sử dụng tiêu chí xác định ĐTĐTK dựa vào tiêu chuẩn phân loại của WHO (2013) sẽ làm giảm tỷ lệ mắc.

Đa số các tác giả nhận thấy vai trò của các yếu tố nguy cơ gây rối loạn dung nạp glucose ở phụ nữ sau sinh giai đoạn sớm. Có thể kể đến các yếu tố thường gặp bao gồm tuổi của mẹ, tăng cân nhiều trước khi mang thai, ĐTĐTK xuất hiện sớm khi mang thai hoặc phải điều trị bằng insulin trong quá trình mang thai và cuối cùng là dựa vào glucose máu huyết tương lúc đói để chẩn đoán rối loạn dung nạp glucose trong quá trình mang thai [8]. Trong nghiên cứu này chỉ nhận thấy mức độ giảm cân nặng sau sinh và chỉ số HbAlc tại thời điểm chẩn đoán ĐTĐTK là yếu tố tiên lượng độc lập đối với rối loạn dung nạp glucose sau khi đã hiệu chỉnh những sai lệch, còn các yếu tố khác thì chưa nhận thấy có vai trò rõ rệt. Có thể do đây là khảo sát một số yếu tố hồi cứu trong một thời gian dài, kể từ lúc chẩn đoán ĐTĐTK đến thời điểm nghiên cứu 6 - 12 tuần sau sinh nên mức độ ảnh hưởng của các yếu tố đó đã thay đổi tương đối nhiều. Có thể nói chỉ số $\mathrm{HbA} 1 \mathrm{c}$ và mức độ giảm cân nặng sau sinh là những yếu tố có giá trị tiên lượng rối loạn dung nạp glucose trong phạm vi đề tài này.

\section{KẾT LUÂN}

Khảo sát 135 phụ nữ ĐTĐTK tại thời điểm sau sinh 12 tuần nhận thấy:

$+42,2 \%$ rối loạn dung nạp glucose trong đó IGT gặp với tỷ lệ cao nhất $(24,4 \%)$ sau đó là $\operatorname{IFG}(11,8 \%)$ và $6 \%$ phối hợp cả 2 tình trạng trên.

$+1,5 \%$ đái tháo đường.

+ Tuổi trung bình, tỷ lệ béo phì trước sinh, tỷ lệ dung nạp glucose bất thường khi mang thai, chỉ số HbAlc tại thời điểm làm NPDNG ở đối tượng rối loạn dung nạp glucose/ ĐTĐ cao hơn có ý nghĩa so với đối tượng dung nạp glucose bình thường.

+ Giảm cân nặng sau sinh $(\mathrm{p}=0,023$; OR $=2,76)$ và chỉ số $\mathrm{HbA} 1 \mathrm{c}$ tại thời điểm thực hiện nghiệm pháp dung nạp khi mang thai ( $p$ $=0,028 ; \mathrm{OR}=4,78$ ) là yếu tố tiên lượng độc lập gây rối loạn dung nạp glucose.

+ Chức năng tế bào $\beta$ (ISSI-2) ở đối tượng rối loạn dung nạp glucose/ ĐTĐ thấp hơn có 
ý nghĩa so với đối tượng có dung nạp bình thường $(\mathrm{p}<0,0001)$.

+ Ở đối tượng IFG: BMI trước sinh, tỷ lệ dung nạp glucose bất thường và nồng độ glucose máu của nghiệm pháp khi mang thai cao hơn có ý nghĩa so với đối tượng IGT, ngược lại giá trị trung bình glucose chung khi làm nghiệm pháp, giá trị trung bình glucose cũng như tỷ lệ dung nạp glucose bất thường tại thời điểm 2 giờ của nghiệm pháp khi mang thai thấp hơn.

+ Chức năng tế bào $\beta$ và kháng insulin ở đối tượng IFG và IGT khác biệt không có ý nghĩa.

+ Rối loạn dung nạp glucose ở phụ nữ có tiền sử ĐTĐTK hay xảy ra ở giai đoạn sớm sau sinh kèm theo biểu hiện giảm chức năng tiết insulin của tế bào $\beta$. NPDNG cần được thực hiện ở tất cả các đối tượng sau sinh.

\section{TÀI LIỆU THAM KHẢO}

1. American Diabetes Association. Diagnosis and classification of diabetes mellitus. Diabetes Care 2009; 32 (suppl 1):S62-S67.

2. Crowther CA, Hiller JE, Moss JR, McPhee AJ, Jeffries W, Robinson JS. Australian Carbohydrate Intolerance study in Pregnancy Women (ACHOIS) Trial Group. Effect of treatment of gestational diabetes mellitus on pregnancy outcomes. N Engl J Med 2005: 352;2477-2486.

3. Landon MB, Spong CY, Thom E, Carpenter M, Ramin SM, Casey B, et al; Eunice Kennedy Shriver National Institute of Child Health and Human Development Maternal-Fetal Medicine Units Network. A multicenter, randomized trial of treatment for mild gestational diabetes. N Engl J Med 2009; 361:1339- 1348 .

4. International Association of Diabetes and Pregnancy Study Groups Consensus Panel. International association of diabetes and pregnancy study groups recommendations on the diagnostic and classification of hyperglycemia in pregnancy. Diabetes Care 2010; 33:676682.

5. Metzger BE, Buchanan TA, Coustan DR, de Leiva A, Dunger DB, Hadden DR, et al. Summary and recommendations of the Fifth International Workshop-Conference on Gestational Diabetes Mellitus. Diabetes Care 2007; 30 (suppl 2):S251S260.

6. Duran A, Sáenz S, Rorrejón MJ, Bordiú $\mathrm{E}$, Del Valle $\mathrm{L}$, Galindo $\mathrm{M}$, et al. Introduction of IADPSG criteria for the screening and diagnosis of gestational diabetes mellitus results in improved pregnancy outcomes at a lower cost in a large cohort of pregnant women: the $\mathrm{St}$ Carlos gestational diabetes study. Diabetes Care 2014; 37:2442-2450.

7. Picón MJ, Murri M, Muñoz A, Fernandez-Garcia JC, Gomez-Huelgas R, Tinahones FJ. Hemoglobin A1c versus oral glucose tolerance test in postpartum diabetes screening. Diabetes Care 2012; 35: 1648-1653.

8. Leuridan L, Wens $\mathrm{J}$, Devlieger $\mathrm{R}$, Verhaeghe J, Mathieu C, Benhalima K. Glucose intolerance in early postpartum in women with gestational diabetes: Who is at increased risk? Primary Care Diabetes 2015; 9, 244-252. 